\title{
Comparative Gamma Delta T Cell Immunology: A Focus on Mycobacterial Disease in Cattle
}

\author{
Brandon L. Plattner ${ }^{1}$ and Jesse M. Hostetter ${ }^{2}$ \\ ${ }^{1}$ Department of Pathobiology, Ontario Veterinary College, University of Guelph, Guelph, ON, Canada N1G 2W1 \\ ${ }^{2}$ Department of Veterinary Pathology, 2720 Veterinary Medicine Complex, College of Veterinary Medicine, Iowa State University, \\ Ames, IA 50011, USA
}

Correspondence should be addressed to Jesse M. Hostetter, jesseh@iastate.edu

Received 13 January 2011; Revised 22 February 2011; Accepted 15 March 2011

Academic Editor: Michael D. Welsh

Copyright (C) 2011 B. L. Plattner and J. M. Hostetter. This is an open access article distributed under the Creative Commons Attribution License, which permits unrestricted use, distribution, and reproduction in any medium, provided the original work is properly cited.

\begin{abstract}
A theme among many pathogenic mycobacterial species affecting both humans and animals is a prolonged asymptomatic or latent period that can last years to decades. The mechanisms that favor progression to active disease are not well understood. Pathogen containment is often associated with an effective cell-mediated or T-helper 1 immune profile. With certain pathogenic mycobacteria, such as Mycobacterium avium subspecies paratuberculosis, a shift to active clinical disease is associated with loss of T-helper 1 immunity and development of an ineffective humoral or T-helper 2 immune response. Recently $\gamma \delta$ T cells have been shown to play a role early in mycobacterial infections and have been hypothesized to influence disease outcome. The purpose of this paper is to compare recent advancements in our understanding of $\gamma \delta \mathrm{T}$ cells in humans, cattle, and mice and to discuss roles of $\gamma \delta$ T cells in host response to mycobacterial infection.
\end{abstract}

\section{Introduction}

The host immune response to mycobacterial infection is complex, and significant differences exist among a diverse group of mycobacterial pathogens and host species infected. A common theme among many pathogenic mycobacterial species in both humans and animals is a prolonged asymptomatic or latent period that can last years to decades. An effective cell-mediated or T helper-1 (Th-1) immune response during latency correlates to control of pathogen proliferation and disease progression. It is interesting that during this latent period bacterial numbers are usually very low and their detection difficult. In ruminants infected with Mycobacterium avium subspecies paratuberculosis (Map), progression from the asymptomatic phase to clinical disease is associated with a loss of Th-1 responses and development of an ineffective humoral or $\mathrm{T}$ helper-2 (Th-2) response [1]. Clinical disease in these animals is characterized by extensive poorly organized macrophage infiltrates into the intestine, which harbor tremendous numbers of Map bacilli. The mechanisms that induce this shift in immune responses remain unknown. A growing area of interest in the pathogenesis of mycobacterial infection is the role of a subset of $\mathrm{T}$ lymphocytes, the gamma delta $(\gamma \delta) \mathrm{T}$ cells. $\gamma \delta \mathrm{T}$ cells are interesting in that they appear to have a diverse set of immunological functions that span innate to adaptive responses. Recently, $\gamma \delta \mathrm{T}$ cells have been shown to play a role early in mycobacterial infection and have been hypothesized to influence the outcome of long-term infection. The purpose of this paper is to compare the recent advances in our understanding of $\gamma \delta \mathrm{T}$ cells in humans, cattle, and mice and to discuss the $\gamma \delta \mathrm{T}$ cell responses that occur during mycobacterial infection in these species.

\section{2. $\gamma \delta$ T Cells}

First described in humans in 1986 [2] and in cattle in 1989 [3], the $\gamma \delta \mathrm{T}$ cell receptor (TCR) has not been well characterized compared to the more widely studied $\alpha \beta$ TCR. Since their discovery, the immunobiology of $\gamma \delta$ T cells has been most studied in humans and mice, and the data have indicated that these cells have a variety of functions 
during both innate and adaptive immunity. Key differences in $\gamma \delta \mathrm{T}$ cell biology exist between species, yet recent data have indicated several common themes that apparently span the species barrier including anatomic distribution and functional capacity: these topics are further discussed in the following sections.

\section{Specialized Anatomic Distribution and Phenotype}

Within lymphoid tissues, $\gamma \delta \mathrm{T}$ cells are considered to be a minor T lymphocyte population, yet $\gamma \delta \mathrm{T}$ cells are enriched in many organs including skin and mucosal surfaces. This distribution suggests a role for these cells during immune surveillance and antigen sampling at surfaces constantly confronted with invading pathogens $[4,5] . \gamma \delta$ T cells are also well represented in peripheral blood mononuclear cells. $\gamma \delta \mathrm{T}$ cells typically represent $1-10 \%$ of circulating T lymphocytes in adult humans and mice and approximately 10-25\% in adult cattle, though this number can be as high as $40 \%$ in young calves [6].

Similar to $\alpha$ and $\beta$ TCR genes, $\gamma$ and $\delta$ TCR genes have variable $(\mathrm{V})$, joining $(\mathrm{J})$, and constant $(\mathrm{C})$ regions. The $\delta$ and $\beta$ genes also contain diversity (D) gene segments [7]. In humans, $\gamma \delta \mathrm{T}$ cell subsets are defined by their $\gamma$ and $\delta$ gene segment usage. In humans, $\gamma \delta \mathrm{T}$ cells from different anatomic sites show preferential $\mathrm{V}$ segment usage suggesting that human $\gamma \delta \mathrm{T}$ cell subsets have distinct functional roles [8]. For example, the two major $\gamma \delta$ T cell subsets in humans are $\mathrm{V} \delta 1+$ and $\mathrm{V} \delta 2+$ cells. $\mathrm{V} \delta 2+$ cells predominate in peripheral blood and have been shown to significantly expand during a variety of infectious diseases including mycobacterial diseases [9]. The V $\delta 1+$ subset is less frequent in the blood, but is the majority subset in tissues $[10,11]$. Expression of additional molecules (CD2, CD4, CD5, CD6, and CD8) on $\gamma \delta$ T cells has also been described in humans, mice, and cattle. There is considerable interspecies variability with respect to these markers suggesting that these molecules are less useful for defining functionally distinct subsets, and there is currently no species-wide $\gamma \delta$ T cell-specific marker $[12,13]$.

The $\gamma \delta$ TCR of cattle has been cloned and characterized, but little is known about how preferential gene segment usage correlates with tissue distribution or functionality $[14,15]$. Surface expression of the cysteine-rich scavenger receptor molecule workshop cluster 1 (WC1) is most commonly used to distinguish $\gamma \delta \mathrm{T}$ cell subsets of cattle, and expression of WC1 appears to be limited to ruminant $\gamma \delta \mathrm{T}$ cells though WC1-like genes have been found in sheep, goats, horses, mice, pigs, and humans [16]. Further subdivision of WC1 expressing cells in cattle has been described (WC1.1, WC1.2, and WC1.3) [17, 18]. As in humans, it is thought that different phenotypes represent functionally distinct $\gamma \delta \mathrm{T}$ cell subsets that preferentially home to different tissue localizations [13]. Based on WC1 molecule expression, bovine $\gamma \delta$ T cells are most frequently divided into two categories: the larger of these subsets has the phenotype $\mathrm{WC1}-\mathrm{CD} 2+\mathrm{CD} 3+$ and is found primarily within splenic red pulp and the intestinal tract, while the second subset has the phenotype WC1+CD2-CD3+ and is found predominantly in peripheral blood. Two additional features that fundamentally distinguish $\alpha \beta$ from $\gamma \delta$ T cells appear to be shared by humans and cattle. First, $\gamma \delta \mathrm{T}$ cells are not clearly defined by surface expression of the CD4 or CD8 accessory molecules, and thus there is no MHC class I or MHC class II restriction. Second, $\gamma \delta \mathrm{T}$ cells recognize unconventional antigens such as phosphorylated microbial metabolites or lipid antigens [19].

\section{Ligands}

Specificity of $\gamma \delta$ T cells to mycobacterial antigens in humans has been described [20]. Protein antigens such as mycobacterial heat shock protein $[21,22]$ and nonprotein $[23,24]$ antigens including phosphoantigens have been shown to induce strong $\gamma \delta \mathrm{T}$ cell responses. In humans, the majority of studies have examined reactive patterns of the $\mathrm{V} \delta 2+$ subset of $\gamma \delta \mathrm{T}$ cells. $\mathrm{V} \delta 2+$ cells recognize low molecular weight nonpeptide phosphate-containing metabolites produced by a variety of bacterial pathogens including mycobacteria [25]. Variations or other important ligands for $\mathrm{V} \delta 2+$ cells include microbial byproducts such as negatively charged alkyl phosphate antigens [26] and positively charged alkylamine antigens [27]. Many of the putative microbial ligands described for human $\gamma \delta$ T cells have autologous counterparts or endogenous metabolites of the mevalonate pathway, which are upregulated during periods of cellular stress suggesting that $\gamma \delta \mathrm{T}$ cells also function during noninfectious processes [28]. Specific ligands for human $V \delta 1+$ cells are less well described. Spada et al. reported that $\mathrm{V} \delta 1+$ cells directly recognized CD1c molecules [11], which may be a mechanism of antigen presentation to $\mathrm{V} \delta 1+$ cells during $M$. leprae infection $[11,29]$.

$\gamma \delta \mathrm{T}$ cell ligands in cattle are not clearly defined. The majority of studies have examined the reactive patterns of $\mathrm{WC} 1+\gamma \delta \mathrm{T}$ cells likely because of their ease of isolation from peripheral blood. An early study by Rhodes et al. demonstrated responsiveness of bovine peripheral blood $\gamma \delta$ T cells from $M$. bovis infected calves to various mycobacterial protein antigens [30]. Work by Welsh et al. confirmed that WC1+ cells respond to both protein and nonprotein $M$. bovis antigens, and that response to mycobacterial proteins was dominant [31]. Vesosky et al. showed that WC1+ cells from healthy calves could respond to stimulation with live mycobacteria, mycobacterial cell wall, and mycobacterial culture filtrate proteins [32]. In this study, the phosphoantigen identified as a human $\gamma \delta \mathrm{T}$ cell ligand (isopentenyl pyrophosphate, IPP) was not recognized by naïve bovine $\gamma \delta \mathrm{T}$ cells [32]. In both humans and cattle, the interactions surrounding $\gamma \delta \mathrm{T}$ cell activation have largely been considered to be MHC-independent [24] and TCR-dependent, although TCR-independent activation has also been shown [33]. Recent work has also demonstrated that purified human and bovine $\gamma \delta \mathrm{T}$ cells can be directly activated by pathogen-associated molecular patterns (PAMPs) in the absence of antigen presenting cells [34], which may have significant implications for the innate role of $\gamma \delta \mathrm{T}$ cells. Though their restriction elements during ligand recognition by bovine $\gamma \delta \mathrm{T}$ cells remain to be fully characterized, it is 
clear that $\gamma \delta$ T cells from both naïve and infected individuals have the capacity to respond to mycobacterial antigens.

\section{Importance of IL-2}

In $\alpha \beta \mathrm{T}$ cells the initial encounter with specific antigen along with the appropriate costimulatory signals (CD28 of $\mathrm{T}$ cell binding B7 of APC) induces the synthesis of IL-2 and increased expression of the $\alpha$ chain of the IL-2 receptor (CD25). Subsequent binding of IL-2 to its high-affinity receptor then triggers progression through the cell cycle, proliferation, and differentiation of naïve T cells [7]. Distinct from their $\alpha \beta \mathrm{T}$ cell counterparts, $\gamma \delta \mathrm{T}$ cells produce minimal amounts of IL-2 upon activation, and the proliferative response of human $\gamma \delta \mathrm{T}$ cells after antigenic stimulation is dependent on CD4+ T cell secretion of IL-2 [35]. Welsh et al. and Smyth et al. in separate studies demonstrated marked upregulation of CD25 on the surface of bovine $\gamma \delta$ T cells after encountering $M$. bovis protein antigens, but there was minimal proliferation without addition of IL$2[31,36]$. Based on these findings, IL-2 is very likely a required secondary signal for activation of $\gamma \delta \mathrm{T}$ cells, which ultimately drives them to proliferation after recognition of mycobacterial antigens.

\section{Effects on Granuloma Formation, Maintenance}

There has been recent interest in the role of $\gamma \delta$ T cells in generation and maintenance of granulomas that develop at mycobacterial infection sites. In a murine model of Map infection, the frequency of granuloma formation was significantly decreased in $\gamma \delta$ TCR depleted mice indicating a potential role of $\gamma \delta$ T cells in the generation of granulomas during mycobacterial infection [37]. In cattle, $\gamma \delta \mathrm{T}$ cells have also been evaluated for a potential role in granuloma formation. Palmer et al. demonstrated that in M. bovis infected calves, $\mathrm{CD} 4+\mathrm{T}$ cell numbers in lymph node granulomas remained constant over time. The number of CD8+ T cells and WC1+ cells was high during early-stage granulomas, but diminished as granulomas matured. The authors suggested that loss of these $\mathrm{T}$ cell subsets during late stages correlates with failure of the immune system to control infection [38]. In contrast, Wangoo et al. showed that late-stage lymph node granulomas from M. bovis-infected calves had significantly greater numbers of WC1 $+\mathrm{T}$ cells compared to early stage lesions, and that the $\mathrm{WC} 1+$ cells were spatially distributed at the peripheral zone near the fibrotic capsule [39]. However, in a separate study evaluating spatial distribution of $\mathrm{T}$ cell subsets, this group was unable to confirm distinct spatial relationships of the $\gamma \delta \mathrm{T}$ cells within the granulomatous lesions [40]. Simutis et al. in 2005 identified $\gamma \delta \mathrm{T}$ cells within poorly organized granulomatous lesions induced by subcutaneous Map injection in a calf model [41]. In 2009, Plattner et al. went on to show in this model that in well-organized (Th-1 polarized granulomas) there was stratification of $\gamma \delta$ T cells with respect to $\mathrm{WC1} 1+$ and WC1- phenotypes. This stratification was lacking in poorly organized granulomas associated with Map infection. The conclusion from this study was that the $\gamma \delta$ T cells subsets had unique roles in directing bovine granuloma formation and function during Map infection [42].

\section{Immediate Effector Function: Cytotoxicity}

Numerous effector functions have been reported for subsets of $\gamma \delta \mathrm{T}$ cells. Activated human $\mathrm{V} \delta 2+\gamma \delta \mathrm{T}$ cells have broad cytotoxic activity. Oliaro et al. demonstrated that $\mathrm{V} \delta 2+$ cells were able to directly lyse Brucella-infected macrophages and reduce intracellular bacterial numbers by the Fas/Fas ligand pathway [43]. Dieli et al. showed that generation of perforin and granzyme by $\mathrm{V} \delta 2+$ cells reduced the viability of both extracellular and intracellular M. tuberculosis [44, $45]$. Fisch et al. specifically examined both major subsets of human $\gamma \delta \mathrm{T}$ cells and demonstrated broad in vitro cytotoxicity by $\mathrm{V} \delta 2+$ cells, but importantly observed that $\mathrm{V} \delta 1+$ cells also exhibited this capacity [46]. In cattle, it is known that cytotoxicity mediated by bovine natural killer (NK) cells reduces intracellular viability of $M$. bovis [47]; however, the evidence for $\gamma \delta \mathrm{T}$ cell-mediated cytotoxicity is less clear. Bovine peripheral blood-derived and antigenstimulated $\gamma \delta \mathrm{T}$ cells (WC1 phenotype not reported, but most likely $\mathrm{WC} 1+$ subset) were unable to mediate nitric oxide production and bacterial killing of Map-infected macrophages [48]. Other data have also suggested that cytotoxicity is a feature of bovine $\gamma \delta \mathrm{T}$ cells during Map infection $[49,50]$.

\section{Immediate Effector Function: Cytokine Secretion}

It has been known for several years that a key mechanism by which $\mathrm{T}$ lymphocytes respond to infectious agents and mediate immune functions is secretion of specific cytokines. Upon recognition of their ligands, $\gamma \delta \mathrm{T}$ cells are able to generate a range of proinflammatory cytokines and antimicrobial peptides [51] and provide an initial barrier until antigen-specific $\alpha \beta$ T cells have been expanded. Cytokine production by $\gamma \delta$ T cell subsets has been analyzed at the gene and protein levels in humans and cattle. Microarray analysis of stimulated human $\mathrm{V} \delta 2+$ cells has shown upregulation of proinflammatory genes such as tumor necrosis factor alpha (TNF- $\alpha$ ), IFN- $\gamma$, macrophage-colony stimulating factor, IL17 , and IL-21 $[52,53]$. However, secretion of some of these proteins by stimulated $\mathrm{V} \delta 2+$ cells has not been confirmed. Initial studies in humans showed that peripheral bloodderived $\gamma \delta \mathrm{T}$ cells rapidly expand and produce IFN $-\gamma$ in response to nonpeptide phosphate antigens [54]. Wang et al. demonstrated that human $V \delta 2+$ cells generate IFN- $\gamma$ and TNF- $\alpha$ as early as 2 hours following exposure to the live bacterial product iso-butylamine. An interesting observation in this study was that production of cytokines was cyclic and limited to periods of direct contact with live bacteria, suggesting that $\gamma \delta \mathrm{T}$ cell activity is focused at the infection site [55]. V $\delta 2+$ production of IFN- $\gamma$ and TNF- $\alpha$ was also confirmed by Wesch et al. [56]. V $\delta 2+$ cells from human 
peripheral blood can be driven towards IL-4 production under specific culture conditions [56]. Depending on the physiologic or pathologic context, subsets of murine $\gamma \delta \mathrm{T}$ cells have also been shown to produce Th2 cytokines [57]. The production of keratinocyte growth factor or connective tissue growth factor by $\gamma \delta \mathrm{T}$ cells suggests more specialized tissue repair functions [19]. Microarray data for humanstimulated $\mathrm{V} \delta 1+$ cells initially demonstrated upregulation of cytokine genes that are considered important during regulatory functions such as IL-10 and IL-11 [52, 53], and recent work has confirmed the ability of $\mathrm{V} \delta 1+$ cells to produce IL-10 as well as transforming growth factor-beta (TGF- $\beta$ ) [58].

In cattle, evidence for cytokine secretion by $\gamma \delta \mathrm{T}$ cell subsets is less clear. Buza et al. correlated IFN- $\gamma$ production with changes in circulating $\gamma \delta \mathrm{T}$ cell populations rather than CD4+ or CD8+ T cells of BCG-vaccinated calves [59]. No effects on disease pathology were observed following depletion of WC $1+\gamma \delta \mathrm{T}$ cells from $M$. bovis-infected calves, though increased antigen-specific IL-4, reduced innate IFN$\gamma$, and reduced IgG2 antibody were observed [60]. WC1+ cells from $M$. bovis-infected calves proliferated strongly when stimulated with $M$. bovis extracts but produced significantly less IFN- $\gamma$ compared to autologous CD4+ T cells [36]. Vesosky et al. demonstrated that while proliferation of bovine $\gamma \delta \mathrm{T}$ cells from healthy cattle could be induced by a variety of mycobacterial antigens, the requirements for IFN- $\gamma$ production were more stringent. Specifically, purified WC1+ cells produced significant amounts of IFN$\gamma$ in response to a nonprotein component of mycobacterial cell wall antigen only when antigen-presenting cells and exogenous IL-2 were added to the cultures [32]. Rogers et al. have further demonstrated that the function of bovine $\gamma \delta \mathrm{T}$ cells varies with the expressed form of WC1. In a series of experiments, they showed that $\mathrm{WC1.1+}$ and WC1.2+ cells had different proliferation potentials to various bacterial stimuli and that the WC1.1+ cells were the major producers of IFN- $\gamma[17,18,61]$. Further, WC1.1+ cells are preferentially recruited to the respiratory tract following intranasal BCG vaccination in calves [62]. In a fetal bovinesevere combined immunodeficient (SCID-bo) xenochimeric mouse model, WC1+ cells did not produce significant IFN- $\gamma$, but were shown to be involved in recruitment of other cells to mycobacterial infection sites [63]. These results support the hypothesis that $\mathrm{WC} 1+$ cells have a role in directing the Th1 bias of the immune response during mycobacterial infections. In contrast to human $\gamma \delta \mathrm{T}$ cells, no published studies document production of IL-4 or other Th2-like cytokines from bovine $\gamma \delta \mathrm{T}$ cells. As is the case for human $\mathrm{V} \delta 1+$ cells, little is known regarding cytokine secretion by WC1 $-\gamma \delta \mathrm{T}$ cells of cattle, though recent work has shown that this subset can be experimentally induced to generate significant amounts of IFN- $\gamma$ [64].

Recently, $\gamma \delta \mathrm{T}$ cells have been shown to play a role during the Th17 response. Th17 responses are defined by the production of IL-17, and are thought to play a critical role in inflammatory responses, particularly at mucosal surfaces [65]. In mice, production of IL-17 has been demonstrated from naïve $\gamma \delta \mathrm{T}$ cells [66]. It has been proposed that $\gamma \delta \mathrm{T}$ cells initiate Th17 responses by upregulation of IL-6 and IL-8, which in turn enhances neutrophil chemotaxis during early bacterial infections [67]. Sutton et al. recently demonstrated that murine $\gamma \delta \mathrm{T}$ cells express the IL-23 receptor and the transcription factor ROR $\gamma \mathrm{T}$ and produce IL-17, IL-21, and IL-22 in response to IL-1 $\beta$ and IL-23 (all features of Th17 response) and that their cytokine production is independent of $\gamma \delta$ TCR ligation [68]. Okamoto Yoshida et al. have recently reported that IL-17 is essential for granuloma formation in mice during mycobacterial infection [69]. IL-17 production by $\gamma \delta \mathrm{T}$ cells has also recently been confirmed in humans [70], but has yet to be identified in cattle.

\section{Specific Effects on Other Cell Types}

The ability of $\gamma \delta \mathrm{T}$ cells to innately produce IFN- $\gamma$ during mycobacterial infection is particularly interesting in the context of mycobacterial diseases. It has been proposed that early IFN- $\gamma$ production at the site of infection by $\gamma \delta \mathrm{T}$ cells could stimulate initial killing of bacteria by macrophages [71]. This could enhance antigen presentation by stimulation of infection site dendritic cells (DCs) to mature and migrate to draining lymph nodes thus initiating adaptive T cell immunity [72]. Moreover, direct influence of $\gamma \delta \mathrm{T}$ cells on DC function has been recently explored. As the primary antigen presenting cells of the innate immune system, DCs are considered to be primary determinants of the efficacy of the $\mathrm{T}$ cell-mediated immune response. It is known that compared to antigen alone, the addition of exogenous IFN- $\gamma$ enhances the maturation of human DCs in vitro and the potency of the ensuing Th1 immune response [73]. $\gamma \delta \mathrm{T}$ cell-mediated enhancement of DC maturation has been documented in vitro following activation of $\mathrm{V} \delta 2+$ phosphoantigen-specific [74] and $\mathrm{V} \delta 1+\mathrm{CD} 1 \mathrm{c}-$ restricted [75] human $\gamma \delta \mathrm{T}$ cell subsets. In these studies, there was increased expression of CD86 on cocultured DCs and enhanced IL-12 production by the DCs, which ultimately resulted in improved priming of downstream $\mathrm{T}$ cell responses. Leslie et al. also have demonstrated that DCs lacking $\gamma \delta \mathrm{T}$ cell interaction (DCs matured by microbial stimuli alone) resulted in "exhausted" DC populations unable to induce efficient Th1 polarization [75]. This response was found to be partially mediated by the cytokines TNF- $\alpha$ and IFN- $\gamma$ in a nonantigen-specific manner [75]. $\mathrm{V} \delta 1+$ cells are thus uniquely positioned to induce DC maturation at infection sites due to their tissue (mucosal surfaces) distribution. A reciprocal interaction where fully mature DCs stimulate $\gamma \delta \mathrm{T}$ cells for sustained innate immune responses has been demonstrated at infection sites and in secondary lymphoid organs [76-78]. DC- $\gamma \delta$ T cell interaction has also been shown to be important in the control of mycobacterial infections in mouse models [79].

In contrast to studies with humans, studies of the cellular interactions between bovine $\gamma \delta \mathrm{T}$ cells and DCs are few. In 1996, Collins et al. demonstrated that neither WC1or $\mathrm{WC1}+$ cells from cattle were stimulated to proliferate in response to allogeneic DCs [80]. These results contrast to CD4+ and CD8+ T cells from these calves, which were strongly induced to proliferate by DCs. Price and Hope 
recently examined interactions between monocyte-derived DCs and WC1+ cells from M. bovis-infected calves in vitro [81]. This study demonstrated that WC1+ cells upregulated surface expression of MHC class II and CD25 (IL-2 receptor) and generated significantly greater amounts of IFN- $\gamma$ when cocultured with DC. Also, the DCs produced significantly greater amounts of IL-12 when cocultured with WC1+ cells. These results further support the hypothesis that in M. bovisinfected cattle, $\gamma \delta \mathrm{T}$ cells are able to provide the initial IFN$\gamma$ burst that is required for full maturation of DCs and that $\gamma \delta \mathrm{T}$ cell-DC interaction can enhance the activation of $\mathrm{MHC}$ class II-restricted $\alpha \beta$ T cells.

Additional roles for $\gamma \delta \mathrm{T}$ cells have been described in a variety of experimental systems. The ability of $\gamma \delta \mathrm{T}$ cells to directly present antigen to $\alpha \beta$ T cells was first demonstrated in cattle [82] and pigs [83]. Collins demonstrated in cattle that B7 molecules were widely expressed on the surface of $\gamma \delta \mathrm{T}$ cells and that antigen-primed WC1+ cells directly induced significant CD4+ T cell proliferation [82]. Similar results have been demonstrated in human $\mathrm{V} \delta 2+[84,85]$ and murine $\gamma \delta$ T cells [86].

\section{Regulatory Function}

Immunomodulatory activity has recently been described for $\gamma \delta \mathrm{T}$ cells of several species including mice [87] and humans $[58,88]$. In the study by Kühl et al., the $\mathrm{V} \delta 1+$ subset was shown to have strong regulatory functions apparently mediated by their production of IL-10 and TGF- $\beta$, yet these $\gamma \delta$ $\mathrm{T}$ cells lack expression of the classic regulatory $\mathrm{T}$ cell marker and transcription factor forkhead box P3 (FoxP3) [58]. Kang et al. were successfully able to induce immunosuppressive function and FoxP3 expression in murine splenic-origin but not human blood-origin $\gamma \delta \mathrm{T}$ cells [89]. An immunomodulatory role for bovine $\gamma \delta \mathrm{T}$ cells was first described in cattle infected with Map where depletion of $\gamma \delta$ T cells was shown to enhance the proliferation of Map antigen-stimulated CD4+ $\mathrm{T}$ cells [49]. Rhodes et al. confirmed regulatory activity by bovine peripheral blood $\gamma \delta$ T cells during $M$. bovis infection when they demonstrated suppression of antigen-specific $\alpha \beta$ T cell proliferation and enhanced production of both IFN- $\gamma$ and TGF- $\beta$ [30]. Jutila and colleagues have also described an immunoregulatory phenotype within subsets of circulating bovine $\gamma \delta \mathrm{T}$ cells using serial gene expression analysis $[90,91]$. Recently, Hoek et al. identified and characterized regulatory function of sorted bovine $\gamma \delta \mathrm{T}$ cells [92]. In contrast to humans and mice, bovine CD4+CD2 $5^{\text {high }}$ FoxP3+ cells lacked ex vivo regulatory activity, and these authors described $\mathrm{T}$ regulatory cell activity by WC1.1+ and WC1.2+ cells with upregulated transcription of IL-10 but not FoxP3 or TGF- $\beta$ genes [92].

\section{Memory Function}

In 2002, Shen et al. demonstrated the capability of primate $\gamma \delta$ $\mathrm{T}$ cells to mount a memory response after microbial infection [93]. Using a macaque tuberculosis model, these authors demonstrated characteristic features of memory $\gamma \delta \mathrm{T}$ cells, which included prolonged recall response upon reinfection.
Interestingly in this study, the expansion of $\mathrm{V} \delta 2+$ cells in the peripheral blood was associated with clearance of detectable bacteremia [93]. In 2003 Dieli et al. demonstrated effector memory subsets of CD45RA-CD27-human V $\delta 2+\mathrm{T}$ cells present in the circulation and within tissues [94].

\section{Conclusions}

With continued exploration of $\gamma \delta \mathrm{T}$ cell functions, it is becoming clear that $\gamma \delta \mathrm{T}$ cells have many roles and can be regulatory or stimulatory during host defense against mycobacterial pathogens [95]. This paper has highlighted key recent findings relevant to the pathogenesis of mycobacterial infections: nonclassical mycobacterial antigens are recognized by $\gamma \delta \mathrm{T}$ cells; $\gamma \delta \mathrm{T}$ cells play key roles in infection site immunopathology, which is potentially mediated by $\gamma \delta \mathrm{T}$ cell production of IL-17; $\gamma \delta \mathrm{T}$ cells lyse infected cells and act as strong producers of IFN- $\gamma$ at infection sites; interactions between $\gamma \delta \mathrm{T}$ cells and DCs leading to mutual activation have potential to influence mycobacterial infection.

Limitations in the study of $\gamma \delta \mathrm{T}$ cell biology such as difficulty obtaining appropriate tissues exist for many species. The study of human and bovine $\gamma \delta \mathrm{T}$ cell biology has been largely focused on in vitro evaluation of peripheral bloodderived $\gamma \delta \mathrm{T}$ cells. Evaluation of the less easily accessed minor $\gamma \delta \mathrm{T}$ cell subsets is important in the future as these subsets have powerful local and downstream effector functions. There is a need for animal modeling systems that allow not only evaluation of multiple tissue-specific $\gamma \delta$ T cell subsets, but also the ability to examine these cells in the context of infection site-specific immunopathology. Cattle display some similarity with humans regarding immunopathology of mycobacterial diseases [96], and this coupled with readilyavailable $\gamma \delta$ T cells makes young calves a strong model choice to study the pathogenesis of mycobacterial disease.

\section{References}

[1] J. R. Stabel, "Transitions in immune responses to Mycobacterium paratuberculosis," Veterinary Microbiology, vol. 77, no. 3-4, pp. 465-473, 2000.

[2] M. B. Brenner, J. McLean, D. P. Dialynas et al., "Identification of a putative second T-cell receptor," Nature, vol. 322, no. 6075, pp. 145-149, 1986.

[3] C. R. Mackay and W. R. Hein, "A large proportion of bovine $\mathrm{T}$ cells express the $\gamma \delta \mathrm{T}$ cell receptor and show a distinct tissue distribution and surface phenotype," International Immunology, vol. 1, no. 5, pp. 540-545, 1989.

[4] M. Girardi, "Immunosurveillance and immunoregulation by $\gamma \delta$ T cells," Journal of Investigative Dermatology, vol. 126, no. 1 , pp. 25-31, 2006.

[5] M. Nanno, T. Shiohara, H. Yamamoto, K. Kawakami, and H. Ishikawa, " $\gamma \delta \mathrm{T}$ cells: firefighters or fire boosters in the front lines of inflammatory responses," Immunological Reviews, vol. 215, no. 1, pp. 103-113, 2007.

[6] R. A. Wilson, A. Zolnai, P. Rudas, and L. V. Frenyo, "Tcell subsets in blood and lymphoid tissues obtained from fetal calves, maturing calve, and adult bovine," Veterinary Immunology \& Immunopathology, vol. 53, no. 1-2, pp. 49-60, 1996. 
[7] C. Janeway, Immunobiology: The Immune System in Health and Disease, Garland Science, New York, NY, USA, 6th edition, 2005.

[8] Y. H. Chien and M. Bonneville, "Gamma delta T cell receptors," Cellular and Molecular Life Sciences, vol. 63, no. 18, pp. 2089-2094, 2006.

[9] H. Das, M. Sugita, and M. B. Brenner, "Mechanisms of V $\delta 1$ $\gamma \delta \mathrm{T}$ cell activation by microbial components," Journal of Immunology, vol. 172, no. 11, pp. 6578-6586, 2004.

[10] B. Falini, L. Flenghi, S. Pileri et al., "Distribution of T cells bearing different forms of the T cell receptor $\gamma / \delta$ in normal and pathological human tissues," Journal of Immunology, vol. 143, no. 8, pp. 2480-2488, 1989.

[11] F. M. Spada, E. P. Grant, P. J. Peters et al., "Self-recognition of CD1 by $\gamma / \delta$ T cells: implications for innate immunity," Journal of Experimental Medicine, vol. 191, no. 6, pp. 937-948, 2000.

[12] A. C. Hayday, " $\gamma \delta$ cells: a right time and a right place for a conserved third way of protection," Annual Review of Immunology, vol. 18, pp. 975-1026, 2000.

[13] N. D. Machugh, J. K. Mburu, M. J. Carol, C. R. Wyatt, J. A. Orden, and W. C. Davis, "Identification of two distinct subsets of bovine $\gamma \delta \mathrm{T}$ cells with unique cell surface phenotype and tissue distribution," Immunology, vol. 92, no. 3, pp. 340-345, 1997.

[14] N. Takeuchi, N. Ishiguro, and M. Shinagawa, "Molecular cloning and sequence analysis of bovine T-cell $\gamma$ and $\delta$ chain genes," Immunogenetics, vol. 35, no. 2, pp. 89-96, 1992.

[15] S. L. Blumerman, C. T. A. Herzig, A. N. Rogers, J. C. Telfer, and C. L. Baldwin, "Differential TCR gene usage between $\mathrm{WC1}^{-}$ and $\mathrm{WC1}^{+}$ruminant $\gamma \delta$ T cell subpopulations including those responding to bacterial antigen," Immunogenetics, vol. 58, no. 8, pp. 680-692, 2006.

[16] P. L. J. Wijngaard, M. J. Metzelaar, N. D. MacHugh, W. I. Morrison, and H. C. Clevers, "Molecular characterization of the WC1 antigen expressed specifically on bovine CD4- $4^{-} D 8^{-}$ $\gamma \delta$ T lymphocytes," Journal of Immunology, vol. 149, no. 10, pp. 3273-3277, 1992.

[17] A. N. Rogers, D. G. Vanburen, E. E. Hedblom, M. E. Tilahun, J. C. Telfer, and C. L. Baldwin, " $\gamma \delta$ T cell function varies with the expressed WC1 coreceptor," Journal of Immunology, vol. 174, no. 6, pp. 3386-3393, 2005.

[18] A. N. Rogers, D. G. VanBuren, B. Zou et al., "Characterization of WC1 co-receptors on functionally distinct subpopulations of ruminant $\gamma \delta$ T cells," Cellular Immunology, vol. 239, no. 2, pp. 151-161, 2006.

[19] S. Beetz, D. Wesch, L. Marischen, S. Welte, H.-H. Oberg, and D. Kabelitz, "Innate immune functions of human $\gamma \delta$ T cells," Immunobiology, vol. 213, no. 3-4, pp. 173-182, 2008.

[20] R. L. Modlin, C. Pirmez, F. M. Hofman et al., "Lymphocytes bearing antigen-specific $\gamma \delta$ T-cell receptors accumulate in human infectious disease lesions," Nature, vol. 339, no. 6225, pp. 544-548, 1989.

[21] A. Haregewoin, G. Soman, R. C. Hom, and R. W. Finberg, "Human $\gamma \delta^{+} \mathrm{T}$ cells respond to mycobacterial heat-shock protein," Nature, vol. 340, no. 6231, pp. 309-312, 1989.

[22] W. Born, L. Hall, A. Dallas et al., "Recognition of a peptide antigen by heat shock-reactive $\gamma \delta$ T lymphocytes," Science, vol. 249, no. 4964, pp. 67-69, 1990.

[23] J. J. Fournié and M. Bonneville, "Stimulation of $\gamma \delta$ T cells by phosphoantigens," Research in Immunology, vol. 147, no. 5, pp. 338-347, 1996.

[24] C. T. Morita, E. M. Beckman, J. F. Bukowski et al., "Direct presentation of nonpeptide prenyl pyrophosphate antigens to human $\gamma \delta$ T cells," Immunity, vol. 3, no. 4, pp. 495-507, 1995.
[25] N. Shrestha, J. A. Ida, A. S. Lubinski, M. Pallin, G. Kaplan, and P. A. Haslett, "Regulation of acquired immunity by gamma delta T-cell/dendritic-cell interactions," Annals of the New York Academy of Sciences, vol. 1062, pp. 79-94, 2005.

[26] Y. Tanaka, C. T. Morita, Y. Tanaka, E. Nieves, M. B. Brenner, and B. R. Bloom, "Natural and synthetic non-peptide antigens recognized by human $\gamma \delta$ T cells," Nature, vol. 375, no. 6527, pp. 155-158, 1995.

[27] J. F. Bukowski, C. T. Morita, and M. B. Brenner, "Human $\gamma \delta$ $\mathrm{T}$ cells recognize alkylamines derived from microbes, edible plants, and tea: implications for innate immunity," Immunity, vol. 11, no. 1, pp. 57-65, 1999.

[28] N. Caccamo, S. Meraviglia, V. Ferlazzo et al., "Differential requirements for antigen or homeostatic cytokines for proliferation and differentiation of human $\mathrm{V} \gamma 9 \mathrm{~V} \delta 2$ naive, memory and effector T cell subsets," European Journal of Immunology, vol. 35, no. 6, pp. 1764-1772, 2005.

[29] P. A. Sieling, D. Jullien, M. Dahlem et al., "CD1 expression by dendritic cells in human leprosy lesions: correlation with effective host immunity," Journal of Immunology, vol. 162, no. 3, pp. 1851-1858, 1999.

[30] S. G. Rhodes, G. R. Hewinson, and M. H. Vordermeier, "Antigen recognition and immunomodulation by $\gamma \delta \mathrm{T}$ cells in bovine tuberculosis," Journal of Immunology, vol. 166, no. 9, pp. 5604-5610, 2001.

[31] M. D. Welsh, H. E. Kennedy, A. J. Smyth, R. M. Girvin, P. Andersen, and J. M. Pollock, "Responses of bovine $\mathrm{WC1}^{+} \gamma \delta$ $\mathrm{T}$ cells to protein and nonprotein antigens of Mycobacterium bovis," Infection \& Immunity, vol. 70, no. 11, pp. 6114-6120, 2002.

[32] B. Vesosky, O. C. Turner, J. Turner, and I. M. Orme, "Gamma interferon production by bovine $\gamma \delta$ T cells following stimulation with mycobacterial mycolylarabinogalactan peptidoglycan," Infection \& Immunity, vol. 72, no. 8, pp. 4612-4618, 2004.

[33] G. Leclercq and J. Plum, "Stimulation of TCR V $\gamma 3$ cells by Gram-negative bacteria," Journal of Immunology, vol. 154, no. 10, pp. 5313-5319, 1995.

[34] J. F. Hedges, K. J. Lubick, and M. A. Jutila, " $\gamma \delta$ T cells respond directly to pathogen-associated molecular patterns," Journal of Immunology, vol. 174, no. 10, pp. 6045-6053, 2005.

[35] M. M. Elloso, H. C. van der Heyde, A. Troutt, D. D. Manning, and W. P. Weidanz, "Human $\gamma \delta \mathrm{T}$ cell subset-proliferative response to malarial antigen in vitro depends on $\mathrm{CD}^{+}{ }^{+} \mathrm{T}$ cells or cytokines that signal through components of the IL2R," Journal of Immunology, vol. 157, no. 5, pp. 2096-2102, 1996.

[36] A. J. Smyth, M. D. Welsh, R. M. Girvin, and J. M. Pollock, "In vitro responsiveness of $\gamma \delta \mathrm{T}$ cells from Mycobacterium bovis-infected cattle to mycobacterial antigens: predominant involvement of $\mathrm{WC1}^{+}$cells," Infection \& Immunity, vol. 69, no. 1, pp. 89-96, 2001.

[37] S. Tanaka, S. Itohara, M. Sato, T. Taniguchi, and Y. Yokomizo, "Reduced formation of granulomata in $\gamma \delta \mathrm{T}$ cell knockout $\mathrm{BALB} / \mathrm{c}$ mice inoculated with Mycobacterium avium subsp. paratuberculosis," Veterinary Pathology, vol. 37, no. 5, pp. 415421, 2000.

[38] M. V. Palmer, W. R. Waters, and T. C. Thacker, "Lesion development and immunohistochemical changes in granulomas from cattle experimentally infected with Mycobacterium bovis," Veterinary Pathology, vol. 44, no. 6, pp. 863-874, 2007. 
[39] A. Wangoo, L. Johnson, J. Gough et al., "Advanced granulomatous lesions in Mycobacterium bovis-infected cattle are associated with increased expression of type I procollagen, $\gamma \delta\left(\mathrm{WC1}^{+}\right) \mathrm{T}$ cells and CD $68^{+}$cells," Journal of Comparative Pathology, vol. 133, no. 4, pp. 223-234, 2005.

[40] E. Liebana, S. Marsh, J. Gough et al., "Distribution and activation of T-lymphocyte subsets in tuberculous bovine lymph-node granulomas," Veterinary Pathology, vol. 44, no. 3, pp. 366-372, 2007.

[41] F. J. Simutis, N. F. Cheville, and D. E. Jones, "Investigation of antigen-specific T-cell responses and subcutaneous granuloma development during experimental sensitization of calves with Mycobacterium avium subsp paratuberculosis," American Journal of Veterinary Research, vol. 66, no. 3, pp. 474-482, 2005.

[42] B. L. Plattner, R. T. Doyle, and J. M. Hostetter, "Gammadelta $\mathrm{T}$ cell subsets are differentially associated with granuloma development and organization in a bovine model of mycobacterial disease," International Journal of Experimental Pathology, vol. 90, no. 6, pp. 587-597, 2009.

[43] J. Oliaro, S. Dudal, J. Liautard, J. B. Andrault, J. P. Liautard, and V. Lafont, "V $\gamma 9 \mathrm{~V} \delta 2 \mathrm{~T}$ cells use a combination of mechanisms to limit the spread of the pathogenic bacteria Brucella," Journal of Leukocyte Biology, vol. 77, no. 5, pp. 652-660, 2005.

[44] F. Dieli, M. Troye-Blomberg, J. Ivanyi et al., "V $\gamma 9 / \mathrm{V} \delta 2$ T lymphocytes reduce the viability of intracellular Mycobacterium tuberculosis," European Journal of Immunology, vol. 30, no. 5, pp. 1512-1519, 2000.

[45] F. Dieli, M. Troye-Blomberg, J. Ivanyi et al., "Granulysindependent killing of intracellular and extracellular Mycobacterium tuberculosis by $\mathrm{V}-\gamma 9 / \mathrm{V} \delta 2 \mathrm{~T}$ lymphocytes," Journal of Infectious Diseases, vol. 184, no. 8, pp. 1082-1085, 2001.

[46] P. Fisch, K. Oettel, N. Fudim, J. E. Surfus, M. Malkovsky, and P. M. Sondel, "MHC-unrestricted cytotoxic and proliferative responses of two distinct human $\gamma / \delta$ T cell subsets to Daudi cells," Journal of Immunology, vol. 148, no. 8, pp. 2315-2323, 1992.

[47] J. J. Endsley, M. A. Endsley, and D. Mark Estes, "Bovine natural killer cells acquire cytotoxic/effector activity following activation with IL-12/15 and reduce Mycobacterium bovis BCG in infected macrophages," Journal of Leukocyte Biology, vol. 79, no. 1, pp. 71-79, 2006.

[48] F. J. Simutis, D. E. Jones, and J. M. Hostetter, "Failure of antigen-stimulated $\gamma \delta \mathrm{T}$ cells and $\mathrm{CD}^{+} \mathrm{T}$ cells from sensitized cattle to upregulate nitric oxide and mycobactericidal activity of autologous Mycobacterium avium subsp. paratuberculosis-infected macrophages," Veterinary Immunology \& Immunopathology, vol. 116, no. 1-2, pp. 1-12, 2007.

[49] R. J. Chiodini and W. C. Davis, "The cellular immunology of bovine paratuberculosis: the predominant response is mediated by cytotoxic gamma/delta $\mathrm{T}$ lymphocytes which prevent $\mathrm{CD}^{+}$activity," Microbial Pathogenesis, vol. 13, no. 6, pp. 447-463, 1992.

[50] R. J. Chiodini and W. C. Davis, "The cellular immunology of bovine paratuberculosis: immunity may be regulated by $\mathrm{CD} 4^{+}$ helper and $\mathrm{CD}^{+}$immunoregulatory $\mathrm{T}$ lymphocytes which down-regulate gamma/delta T-cell cytotoxicity," Microbial Pathogenesis, vol. 14, no. 5, pp. 355-367, 1993.

[51] B. Agerberth, J. Charo, J. Werr et al., "The human antimicrobial and chemotactic peptides LL-37 and $\alpha$-defensins are expressed by specific lymphocyte and monocyte populations," Blood, vol. 96, no. 9, pp. 3086-3093, 2000.
[52] E. Kress, J. F. Hedges, and M. A. Jutila, "Distinct gene expression in human $\mathrm{V} \delta 1$ and $\mathrm{V} \delta 2 \gamma \delta \mathrm{T}$ cells following nonTCR agonist stimulation," Molecular Immunology, vol. 43, no. 12, pp. 2002-2011, 2006.

[53] R. L. O’Brien, C. L. Roark, N. Jin et al., “ $\gamma \delta$ T-cell receptors: functional correlations," Immunological Reviews, vol. 215, no. 1, pp. 77-88, 2007.

[54] V. E. García, P. A. Sieling, J. Gong et al., "Single-cell cytokine analysis of $\gamma \delta \mathrm{T}$ cell responses to nonpeptide mycobacterial antigens," Journal of Immunology, vol. 159, no. 3, pp. 13281335, 1997.

[55] L. Wang, H. Das, A. Kamath, and J. F. Bukowski, "Human $\mathrm{V} \gamma 2 \mathrm{~V} \delta 2 \mathrm{~T}$ cells produce IFN- $\gamma$ and TNF- $\alpha$ with an on/off/on cycling pattern in response to live bacterial products," Journal of Immunology, vol. 167, no. 11, pp. 6195-6201, 2001.

[56] D. Wesch, A. Glatzel, and D. Kabelitz, "Differentiation of resting human peripheral blood $\gamma \delta \mathrm{T}$ cells toward Th1- or Th2-phenotype," Cellular Immunology, vol. 212, no. 2, pp. 110-117, 2001.

[57] Y.-S. Hahn, C. Taube, N. Jin et al., "Different potentials of $\gamma \delta \mathrm{T}$ cell subsets in regulating airway responsiveness: $\mathrm{V} \gamma 1^{+}$cells, but not $\mathrm{V} \gamma 4^{+}$cells, promote airway hyperreactivity, Th2 cytokines, and airway inflammation," Journal of Immunology, vol. 172, no. 5, pp. 2894-2902, 2004.

[58] A. A. Kühl, N. N. Pawlowski, K. Grollich et al., "Human peripheral $\gamma \delta \mathrm{T}$ cells possess regulatory potential," Immunology, vol. 128, no. 4, pp. 580-588, 2009.

[59] J. Buza, T. Kiros, A. Zerihun, I. Abraham, and G. Ameni, "Vaccination of calves with Mycobacteria bovis Bacilli Calmete Guerin (BCG) induced rapid increase in the proportion of peripheral blood $\gamma \delta \mathrm{T}$ cells," Veterinary Immunology \& Immunopathology, vol. 130, no. 3-4, pp. 251-255, 2009.

[60] H. E. Kennedy, M. D. Welsh, D. G. Bryson et al., "Modulation of immune responses to Mycobacterium bovis in cattle depleted of $\mathrm{WC}^{+} \gamma \delta \mathrm{T}$ cells," Infection \& Immunity, vol. 70, no. 3, pp. 1488-1500, 2002.

[61] A. N. Rogers, D. G. Vanburen, E. Hedblom, M. E. Tilahun, J. C. Telfer, and C. L. Baldwin, "Function of ruminant $\gamma \delta$ T cells is defined by WC1.1 or WC1.2 isoform expression," Veterinary Immunology \& Immunopathology, vol. 108, no. 1-2, pp. 211217, 2005.

[62] S. Price, M. Davies, B. Villarreal-Ramos, and J. Hope, "Differential distribution of $\mathrm{WC}^{+} \gamma \delta \mathrm{TCR}^{+} \mathrm{T}$ lymphocyte subsets within lymphoid tissues of the head and respiratory tract and effects of intranasal M. bovis BCG vaccination," Veterinary Immunology \& Immunopathology, vol. 136, no. 1-2, pp. 133137, 2010.

[63] R. A. Smith, J. M. Kreeger, A. J. Alvarez et al., "Role of CD8 ${ }^{+}$ and $\mathrm{WC}-1^{+} \gamma / \delta \mathrm{T}$ cells in resistance to Mycobacterium bovis infection in the SCID-bo mouse," Journal of Leukocyte Biology, vol. 65, no. 1, pp. 28-34, 1999.

[64] W. C. Johnson, R. G. Bastos, W. C. Davis, and W. L. Goff, "Bovine $\mathrm{WC1}^{-} \gamma \delta \mathrm{T}$ cells incubated with IL-15 express the natural cytotoxicity receptor CD335 (NKp46) and produce IFN- $\gamma$ in response to exogenous IL-12 and IL-18," Developmental \& Comparative Immunology, vol. 32, no. 8, pp. 1002-1010, 2008.

[65] P. Miossec, T. Korn, and V. K. Kuchroo, "Interleukin-17 and type 17 helper T cells," The New England Journal of Medicine, vol. 361, no. 9, pp. 848-898, 2009.

[66] E. Lockhart, A. M. Green, and J. L. Flynn, "IL-17 production is dominated by $\gamma \delta \mathrm{T}$ cells rather than CD4 T cells during Mycobacterium tuberculosis infection," Journal of Immunology, vol. 177, no. 7, pp. 4662-4669, 2006. 
[67] D. J. Cua and C. M. Tato, "Innate IL-17-producing cells: the sentinels of the immune system," Nature Reviews Immunology, vol. 10, no. 7, pp. 479-489, 2010.

[68] C. E. Sutton, S. J. Lalor, C. M. Sweeney, C. F. Brereton, ED. C. Lavelle, and K. H. G. Mills, "Interleukin-1 and IL-23 induce innate IL-17 production from $\gamma \delta \mathrm{T}$ cells, amplifying Th17 responses and autoimmunity," Immunity, vol. 31, no. 2, pp. 331-341, 2009.

[69] Y. Okamoto Yoshida, M. Umemura, A. Yahagi et al., "Essential role of IL-17A in the formation of a mycobacterial infectioninduced granuloma in the lung," Journal of Immunology, vol. 184, no. 8, pp. 4414-4422, 2010.

[70] K. J. Ness-Schwickerath, C. Jin, and C. T. Morita, "Cytokine requirements for the differentiation and expansion of IL17A- and IL-22-producing human Vgamma2Vdelta2 T cells," Journal of Immunology, vol. 184, no. 12, pp. 7268-7280, 2010.

[71] K. Kubota, "Innate IFN- $\gamma$ production by subsets of natural killer cells, natural killer T cells and $\gamma \delta \mathrm{T}$ cells in response to dying bacterial-infected macrophages," Scandinavian Journal of Immunology, vol. 71, no. 3, pp. 199-209, 2010.

[72] C. Münz, R. M. Steinman, and S. I. Fujii, "Dendritic cell maturation by innate lymphocytes: coordinated stimulation of innate and adaptive immunity," Journal of Experimental Medicine, vol. 202, no. 2, pp. 203-207, 2005.

[73] G. Shankar, L. A. Pestano, and M. L. Bosch, "Interferon- $\gamma$ added during Bacillus Calmette-Guerin induced dendritic cell maturation stimulates potent T1 immune responses," Journal of Translational Medicine, vol. 1, article 7, 2003.

[74] L. Conti, R. Casetti, M. Cardone et al., "Reciprocal activating interaction between dendritic cells and pamidronatestimulated $\gamma \delta \mathrm{T}$ cells: role of CD86 and inflammatory cytokines," Journal of Immunology, vol. 174, no. 1, pp. 252260, 2005.

[75] D. S. Leslie, M. S. Vincent, F. M. Spada et al., "CD1mediated $\gamma / \delta$ T cell maturation of dendritic cells," Journal of Experimental Medicine, vol. 196, no. 12, pp. 1575-1584, 2002.

[76] J. Ismaili, V. Olislagers, R. Poupot, J. J. Fournié, and M. Goldman, "Human $\gamma \delta$ T cells induce dendritic cell maturation," Clinical Immunology, vol. 103, no. 3 I, pp. 296-302, 2002.

[77] A. Martino, R. Casetti, A. D’Alessandri, A. Sacchi, and F. Poccia, "Complementary function of $\gamma \delta$ T-lymphocytes and dendritic cells in the response to isopentenyl-pyrophosphate and lipopolysaccharide antigens," Journal of Clinical Immunology, vol. 25, no. 3, pp. 230-237, 2005.

[78] M.-C. Devilder, S. Maillet, I. Bouyge-Moreau, E. Bonnadieu, M. Bonneville, and E. Scotet, "Potentiation of antigenstimulated $\mathrm{V} \gamma 9 \mathrm{~V} \delta 2 \mathrm{~T}$ cell cytokine production by immature dendritic cells (DC) and reciprocal effect on DC maturation," Journal of Immunology, vol. 176, no. 3, pp. 1386-1393, 2006.

[79] F. Dieli, N. Caccamo, S. Meraviglia et al., "Reciprocal stimulation of $\gamma \delta \mathrm{T}$ cells and dendritic cells during the anti-mycobacterial immune response," European Journal of Immunology, vol. 34, no. 11, pp. 3227-3235, 2004.

[80] R. A. Collins, P. Sopp, K. I. Gelder, W. I. Morrison, and C. J. Howard, "Bovine $\gamma / \delta \mathrm{TcR}^{+} \mathrm{T}$ lymphocytes are stimulated to proliferate by autologous Theileria annulata-infected cells in the presence of interleukin-2," Scandinavian Journal of Immunology, vol. 44, no. 5, pp. 444-452, 1996.

[81] S. J. Price and J. C. Hope, "Enhanced secretion of interferon- $\gamma$ by bovine $\gamma \delta$ T cells induced by coculture with Mycobacterium bovis-infected dendritic cells: evidence for reciprocal activating signals," Immunology, vol. 126, no. 2, pp. 201-208, 2009.
[82] R. A. Collins, D. Werling, S. E. Duggan, A. P. Bland, K. R. Parsons, and C. J. Howard, " $\gamma \delta \mathrm{T}$ cells present antigen to $\mathrm{CD}^{+} \alpha \beta$ T cells," Journal of Leukocyte Biology, vol. 63, no. 6, pp. 707-714, 1998.

[83] H. H. Takamatsu, M. S. Denyer, and T. E. Wileman, "A sub-population of circulating porcine $\gamma \delta \mathrm{T}$ cells can act as professional antigen presenting cells," Veterinary Immunology \& Immunopathology, vol. 87, no. 3-4, pp. 223-224, 2002.

[84] M. Brandes, K. Willimann, and B. Moser, "Immunology: professional antigen-presentation function by human $\gamma \delta$ cells," Science, vol. 309, no. 5732, pp. 264-268, 2005.

[85] M. Brandes, K. Willimann, G. Bioley et al., "Cross-presenting human $\gamma \delta$ T cells induce robust $\mathrm{CD}^{+} \alpha \beta$ T cell responses," Proceedings of the National Academy of Sciences of the United States of America, vol. 106, no. 7, pp. 2307-2312, 2009.

[86] L. Cheng, Y. Cui, H. Shao et al., "Mouse $\gamma \delta$ T cells are capable of expressing MHC class II molecules, and of functioning as antigen-presenting cells," Journal of Neuroimmunology, vol. 203 , no. 1, pp. 3-11, 2008.

[87] K. Uezu, K. Kawakami, K. Miyagi et al., "Accumulation of $\gamma \delta \mathrm{T}$ cells in the lungs and their regulatory roles in Th1 response and host defense against pulmonary infection with Cryptococcus neoformans," Journal of Immunology, vol. 172, no. 12, pp. 7629-7634, 2004.

[88] L. R. V. Antonelli, W. O. Dutra, R. R. Oliveira et al., "Disparate immunoregulatory potentials for double-negative $\left(\mathrm{CD} 4^{-} \mathrm{CD} 8^{-}\right) \alpha \beta$ and $\gamma \delta \mathrm{T}$ cells from human patients with cutaneous leishmaniasis," Infection \& Immunity, vol. 74, no. 11, pp. 6317-6323, 2006.

[89] N. Kang, L. Tang, X. Li et al., "Identification and characterization of Foxp $3^{+} \gamma \delta$ T cells in mouse and human," Immunology Letters, vol. 125, no. 2, pp. 105-113, 2009.

[90] J. F. Hedges, D. Cockrell, L. Jackiw, N. Meissner, and M. A. Jutila, "Differential mRNA expression in circulating $\gamma \delta \mathrm{T}$ lymphocyte subsets defines unique tissue-specific functions," Journal of Leukocyte Biology, vol. 73, no. 2, pp. 306-314, 2003.

[91] N. Meissner, J. Radke, J. F. Hedges et al., "Serial analysis of gene expression in circulating $\gamma \delta \mathrm{T}$ cell subsets defines distinct immunoregulatory phenotypes and unexpected gene expression profiles," Journal of Immunology, vol. 170, no. 1, pp. 356-364, 2003.

[92] A. Hoek, V. P. M. G. Rutten, J. Kool et al., "Subpopulations of bovine $\mathrm{WC}^{+} \gamma \delta \mathrm{T}$ cells rather than $\mathrm{CD} 4^{+} \mathrm{CD} 25^{\text {high }} \mathrm{Foxp} 3^{+}$ $\mathrm{T}$ cells act as immune regulatory cells ex vivo," Veterinary Research, vol. 40, no. 1, 2009.

[93] Y. Shen, D. Zhou, L. Qiu et al., "Adaptive immune response of $\mathrm{V} \gamma 2 \mathrm{~V} \delta 2^{+} \mathrm{T}$ cells during mycobacterial infections," Science, vol. 295, no. 5563, pp. 2255-2258, 2002.

[94] F. Dieli, F. Poccia, M. Lipp et al., "Differentiation of effector/memory V $\delta 2 \mathrm{~T}$ cells and migratory routes in lymph nodes or inflammatory sites," Journal of Experimental Medicine, vol. 198, no. 3, pp. 391-397, 2003.

[95] W. R. Waters, M. V. Palmer, T. C. Thacker et al., "Tuberculosis immunity: opportunities from studies with cattle," Clinical and Developmental Immunology, vol. 2011, Article ID 768542, 11 pages, 2011.

[96] J. J. Endsley, W. R. Waters, M. V. Palmer et al., "The calf model of immunity for development of a vaccine against tuberculosis," Veterinary Immunology \& Immunopathology, vol. 128, no. 1-3, pp. 199-204, 2009. 

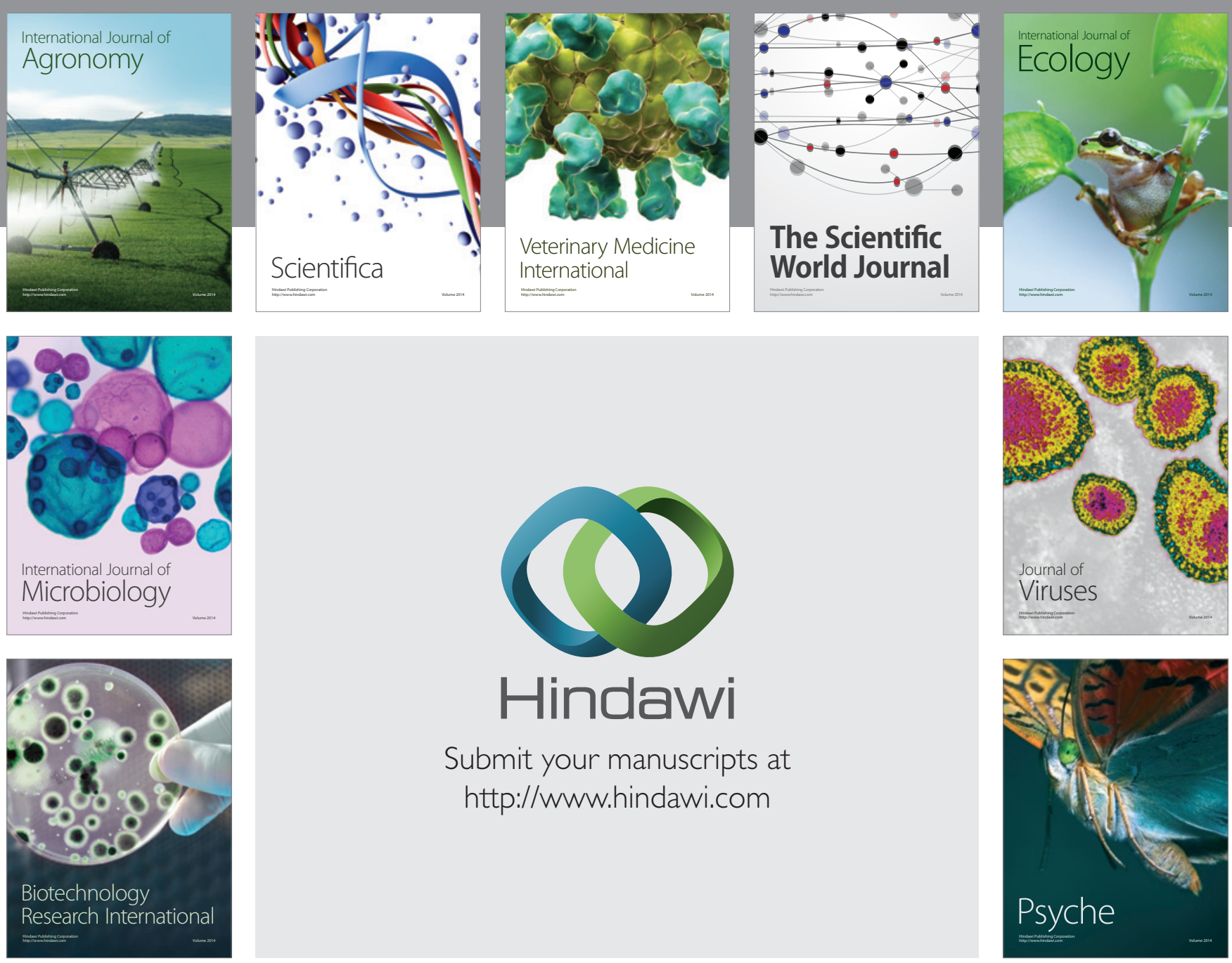

Submit your manuscripts at

http://www.hindawi.com
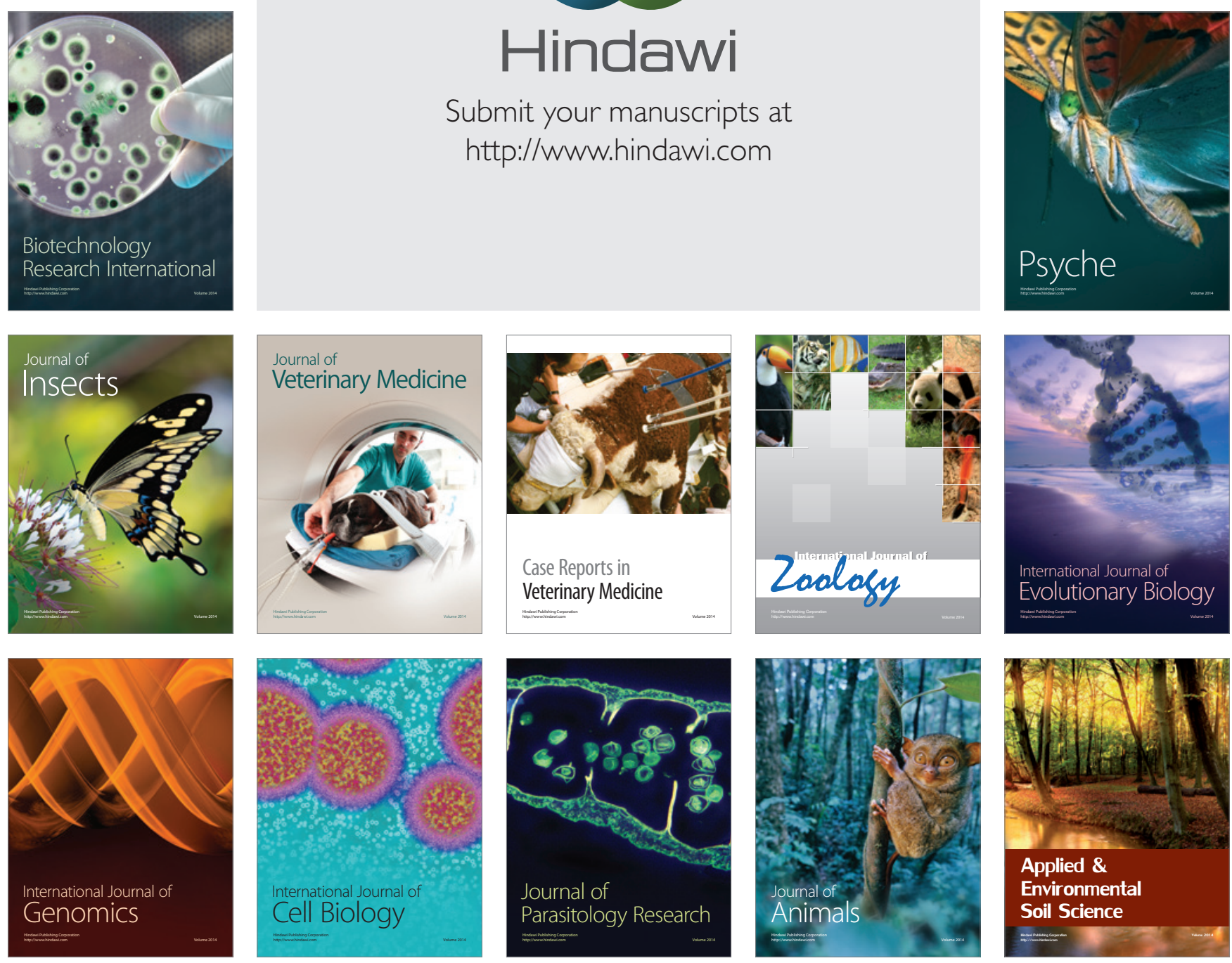